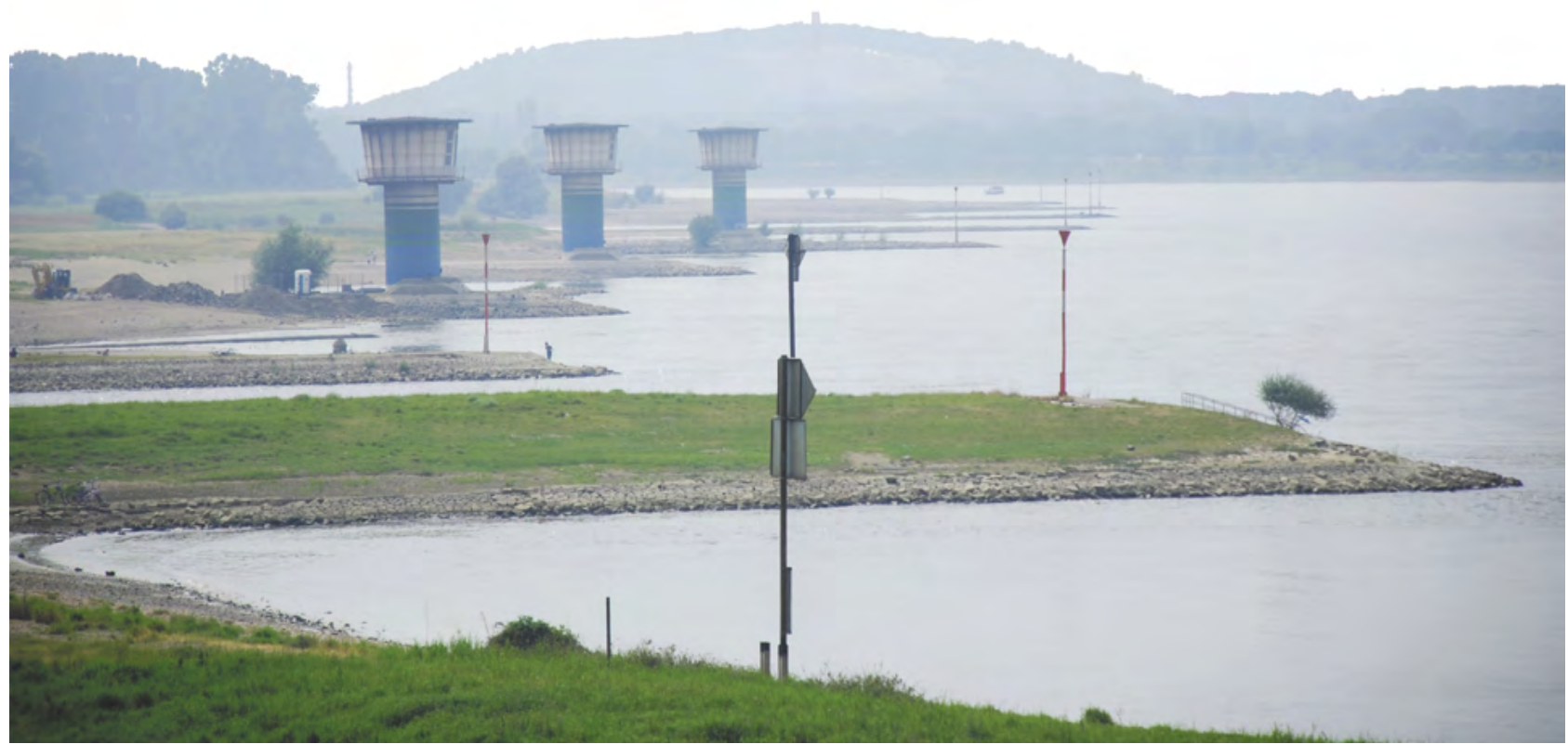

Faculté d'architecture, d'ingénierie architecturale, d'urbanisme de l'Université catholique de Louvain 


\title{
De l'art de (dé)construire
}

\author{
Nicolas Van Oost
}

Une loi de 1939 a fixé, en Belgique, les rôles et les relations du maître de l'ouvrage, de l'architecte et de l'entrepreneur de construction. Aujourd'hui, ce triangle est ébranlé sur chacune de ses bases.

D'un côté, le maître d'ouvrage public ou privé s'éloigne graduellement de l'utilisateur final de l'ouvrage, allant jusqu'à déléguer entièrement la maîtrise d'ouvrage à des spécialistes externes qui n'ont plus aucun rapport avec les utilisateurs.

D'un autre côté, le maître d'œuvre (l'architecte) perd son identité et sa cohérence en devenant une équipe multidisciplinaire, agglomérant un grand nombre de spécialistes souvent imposés par les cadres légaux, et qui chacun cherchent à imprimer leur marque au projet pour justifier leurs revenus. Dans ce cadre, l'architecte éprouve de plus en plus de difficultés à jouer son rôle de chef d'orchestre dans le brouhaha des intermédiaires, alors qu'il reste responsable de l'ouvrage livré.

Enfin, l'entreprise de construction, à quelques exceptions remarquables, se mute souvent en gestionnaire financier et juridique, délaissant sa mission de réaliser, rendre réel, le projet. Elle se soumet à la loi du moins cher qui la fait renoncer à la recherche de l'équilibre entre expérience, qualité et coût.

En procédure de construction et réalisation, le phénomène est accru. Dans ce type de montage, le concept est initié par l'architecte, puis il est discuté avec l'entreprise en vue d'optimiser les méthodes constructives et le coût. Dans les meilleurs cas, le projet peut être un succès, mais les rôles sont renversés : l'architecte est dominé par l'entreprise de construction qui privilégie son budget et éloigne alors les concepteurs du maître de l'ouvrage et de l'utilisateur du bâti. L'éloignement, la dilution du lien, est dramatiquement accentué quand des contraintes supplémentaires sont introduites dans le projet, au niveau de l'offre, comme le financement, la maintenance, voire même la gestion opérationnelle.

Mais fi de nostalgie, revenons aux origines des mots, ou tout au moins d'un mot, "œuvre", qui fonde le triangle : maître d'ouvrage, maître d'œuvre, ouvrier.
On pourrait être tenté de penser que "travailleur", au lieu d'"ouvrier", serait plus approprié, plus noble. Or ce mot renferme une souffrance sociale, tandis que l'ouvrier est en premier lieu celui qui met en œuvre le concept !

En effet, il apparaît essentiel de renouer le dialogue et de retrouver les fondamentaux. L'on doit revenir sur le chantier ensemble, admirer un geste précis, dialoguer, serrer une main qui façonne... Permettre également de travailler au juste prix, dans un délai raisonnable, et en toute sécurité.

L'actualité nous abreuve de nouvelles tantôt affligeantes, tantôt porteuses d'espoir lorsqu'elles évoquent le progrès en termes de durabilité, de bien être, de simplicité. Avant tout, nous sommes face, ici, à une question que nous devons dénouer ensemble.

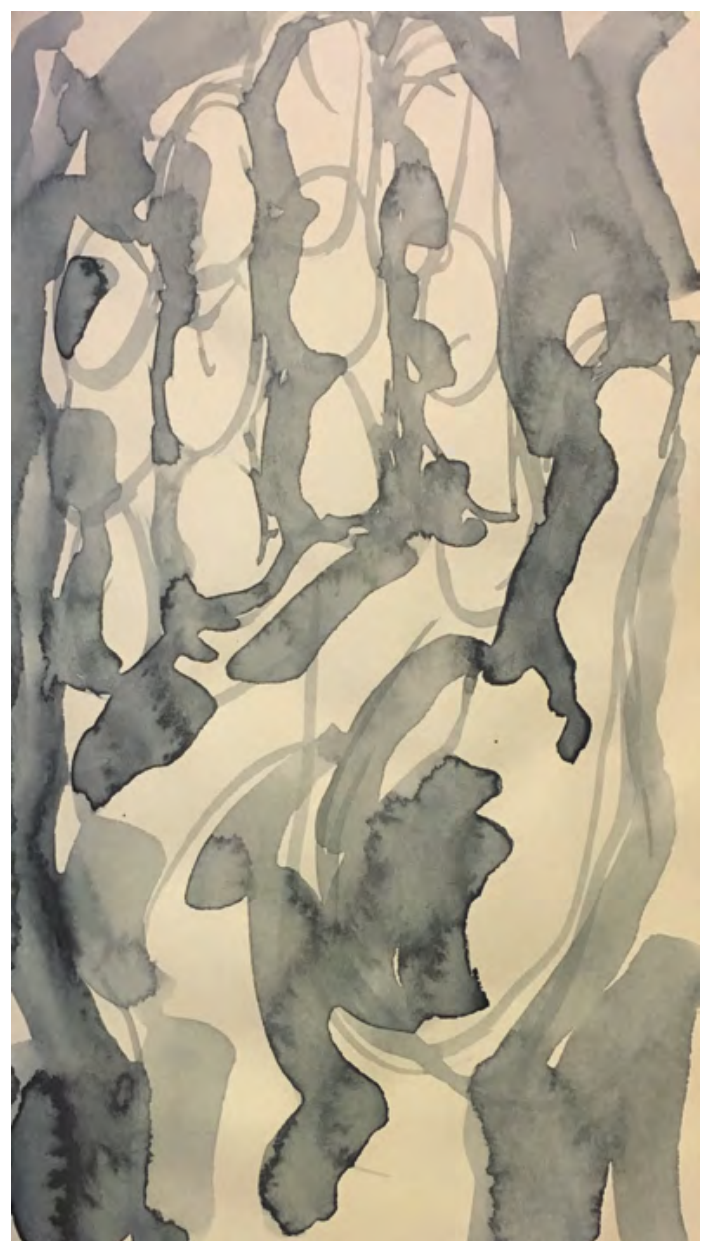

